\title{
Multiple Organ Dysfunction Syndrome (MODS): Is It Preventable or Inevitable?*
}

\author{
Ayman El-Menyar ${ }^{1,2 \#}$, Hassan Al Thani ${ }^{3}$, El Rasheid Zakaria ${ }^{4}$, Ahmad Zarour $^{3}$, Mazin Tuma ${ }^{3}$, \\ Husham AbdulRahman ${ }^{3}$, Ashok Parchani ${ }^{3}$, Ruben Peralta ${ }^{3}$, Rifat Latifi ${ }^{2,3,5}$ \\ ${ }^{1}$ The Clinical Research, Trauma Surgery, Hamad Medical Corporation (HMC), Doha, Qatar; ${ }^{2}$ Clinical Medicine, Weill Cornell \\ Medical School, Doha, Qatar; ${ }^{3}$ Trauma Surgery, Hamad Medical Corporation (HMC), Doha, Qatar; ${ }^{4}$ Medical Research Center, \\ Hamad Medical Corporation (HMC), Doha, Qatar; ${ }^{5}$ Department of Surgery, University of Arizona, Tucson, Arizona, USA. \\ Email: "aymanco65@yahoo.com
}

Received September $26^{\text {th }}, 2012$; revised November $11^{\text {th }}, 2012$; accepted November $24^{\text {th }}, 2012$

\begin{abstract}
Multiple organ dysfunction syndrome (MODS) is a systemic, dysfunctional inflammatory response that requires long intensive care unit (ICU) stay. It is characterized with high mortality rate depending on the number of organs involved. It has been recognized that organ failure does not occur as an all-or-none rule, but rather a range of organ dysfunction exists resulting in clinical organ failure. In the absence of a gold standard scoring or tool for early diagnosis or prediction of MODS, a novel bio-clinical scoring is mandatory. Moreover, understanding the pathophysiology of MODS in medical, surgical and trauma, ICUs should take a priority to achieve a favorable outcome. Herein we reviewed the literatures published in English language through the research engines (MEDLINE, Scopus, and EBASE) from 1982 to 2011 using key words: "multiorgan dysfunction", "organ failure", "intensive care units" to highlight the definition, mechanism, diagnosis and prediction of MODS particularly at its earliest stages. Bring up new bio-clinical scoring to a stage where it is ready for field trials will pave the way for implementing new risk-stratification strategy in the intensive care to reduce the morbidity and mortality and save resources. Prospective studies are needed to answer our question and to shift MODS from an inevitable to a preventable disorder.
\end{abstract}

Keywords: Multiorgan Dysfunction; Failure; Intensive Care Units

\section{Introduction}

Multiple organ dysfunction syndrome (MODS) is a systemic, dysfunctional inflammatory response that requires long intensive care unit (ICU) stay and has high mortality rate of $27 \%-100 \%$ depending on the number of organs involved [1-3]. However, there is no gold standard scoring system for MODS and also, the available registries and studies are not enough to understand, diagnose or predict the occurrence of MODS across the different types of ICUs. Herein we reviewed the literatures published in English language through the research engines (MEDLINE, Scopus, and EBASE) from 1982 to 2011 using key words: "multiorgan dysfunction", "organ failure", "intensive care units" to highlight the definition, mechanism, diagnosis and prediction of MODS particularly at its earliest stages. Non-English articles, case reports, outdated abstracts, and unpublished data were excluded.

\footnotetext{
*All authors read and approved the manuscript; there is no conflict of interest and no financial issues to declare.

${ }^{\#}$ Corresponding author.
}

\section{Mechanism of Multiple Organ Dysfunction Syndrome}

MODS is the leading cause of mortality in patients who survived the initial hours after trauma [2]. Moreover, MODS represents the most common cause of utilization of hospital resources. Initially MODS was thought to be an overwhelming, uncontrolled sepsis response, this was modified with the realization of the bimodal model of MODS (Figure 1) and the recognition that early MODS was unrelated to sepsis. In general, the cause of post injury MODS involves a mixed layering of patient, injury and treatment factors (Figure 1). The dysregulated immunological response is the crucial factor in the pathophysiology of post injury MODS [3].

\section{Cycle and Stages of MODS}

Patients with a heterogeneous trauma load and clinical picture are resuscitated into a similar state of systemic hyperinflammation, termed systemic inflammatory response syndrome (SIRS). This might be both beneficial 


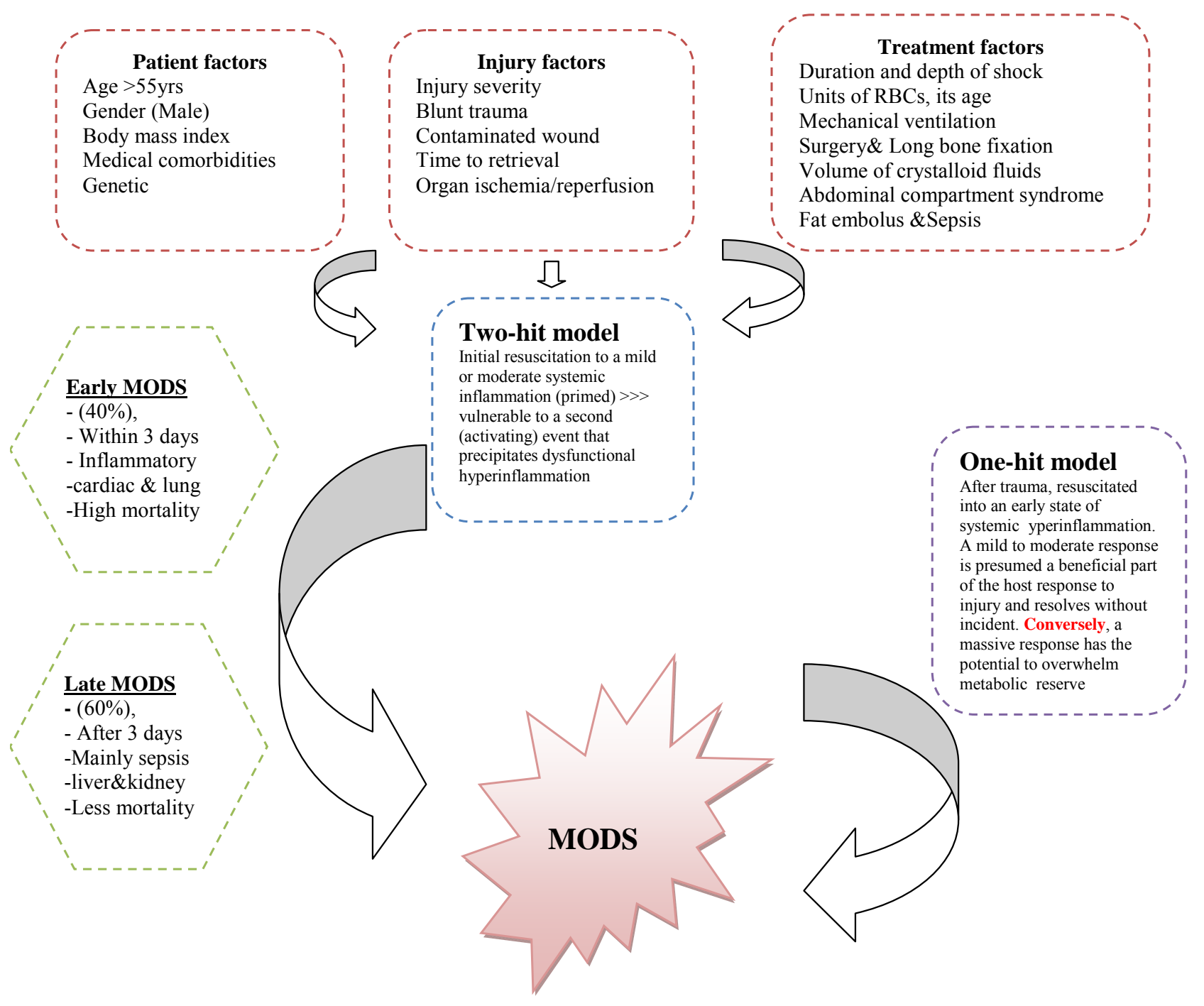

Injury $>>$ shock $>>$ whole body hypoperfusion $>>$ resuscitation $>>$ reperfusion of ischaemic gut $>>$ release of cytokines (IL6, IL8 and IL10) $>>$ proinflammatory lipids and proteins from the reperfused splanchnic bed $>>$ these mediators return to vascular circulation via lymphatics $>>$ prime PMNs $>>$ PMNs mobilise into vascular circulation $>>$ a significant neutrophillia at $3 \mathrm{~h}$ postinjury $>>$ "vulnerable window" $>>$ A second hit during this period??: Yes $>>$ precipitate MOF, No $>>$ eutrophillia normally resolves without endorgan damage.

Figure 1. Causes, mechanism and types of multiorgan dysfunction syndrome.

and compensatory mechanism in the early stage of the disease, resolving in the majority of patients as they recover. However, organ failure may occur if this inflamematory response is exaggerated or sustained, eventually resulting in MODS. The initial magnitude of postinjury inflammatory response is depend on the amount of tissue injury, the degree of shock and the presence of host factors [4]. Patients who develop MODS frequently have early respiratory dysfunction, which is the major contributor to early MODS, occurring in $99 \%$ of postinjury MODS. Lung dysfunction precedes cardiac, hepatic and renal dysfunction $[1,5]$. The other dysfunctional organ systems can be associated with or without sepsis, and occur generally after $72 \mathrm{hrs}$ of the primary insult (Late MODS). Late MODS patients require a second hit to progress to organ failure, and this hit is often sepsis. Nosocomial pneumonia, a common ICU complication, is the major infection associated with or precipitate late MODS $[1,6]$.

\section{MODS-Related Studies}

Most of studies have included heterogonous population including medical and surgical patients who developed organ failure from a wide range of causes [7]. It is now recognized that organ failure does not occur as an all-or- 
none phenomenon, but rather that a range of organ dysfunction exists leading up to clinical failure [7]. It has been suggested that this continuous process of varying levels of organ function is designated "MODS" [8]. This change in the understanding of organ failure as a continuous process has led to the development of a number of scoring systems that attempt to quantitate the degree of organ failure $[9,10]$. These variations in the definition of organ failure and the study of heterogeneous patient populations have made it difficult to establish the accurate incidence of organ failure in a given homogeneous population. Figure 2 shows the incidence of single and multiorgan failure (SOF and MOF) in various studies [11$15]$.

\section{Independent Predictors for MOF}

For early risk stratification (12 hrs postinjury), several modifiable and non-modifiable predictors have been reported: high injury severity, amount of red blood cell transfusion, age of transfused products, age greater than 55 years old, high base deficit, uncorrected lactate at 12 $24 \mathrm{hrs}$ postinjury, obesity, male gender and abdominal compartment syndrome [1]. However, even during this early period, MOF already has been triggered and may be inevitable $[1,16]$.

\section{Scoring and Criteria}

The pathophysiology of MODS is varying according to the mechanism of injury in the medical versus non-medical (trauma and surgical) ICUs. Certain criteria should be taken into consideration when assessing the value of any scoring system in clinical practice $[17,18]$. These criteria should include reliability, validity and the ability of a scoring system to unmask temporal changes in organ dysfunction if measured sequentially $[18,19]$. Studies evaluated the comparative prognostic value of the commonly used organ dysfunction scoring systems concluded that some standardization of the included variables is needed before introducing a scoring tool in everyday practice [20,21]. In the absence of a gold standard scoring or tool for diagnosis or prediction of MODS, validation is required to evaluate the association of different scores with objective, adverse outcomes, clinical status and resource utilization. Table 1 shows the diver sity of scoring systems for MOF [10,12,13,15-20]. Sauaia et al. [21] reported that both Denver and Marshall MOF scores perform reasonably well as indicators of unfavorable outcomes in critically ill patients; with the Denver MOF

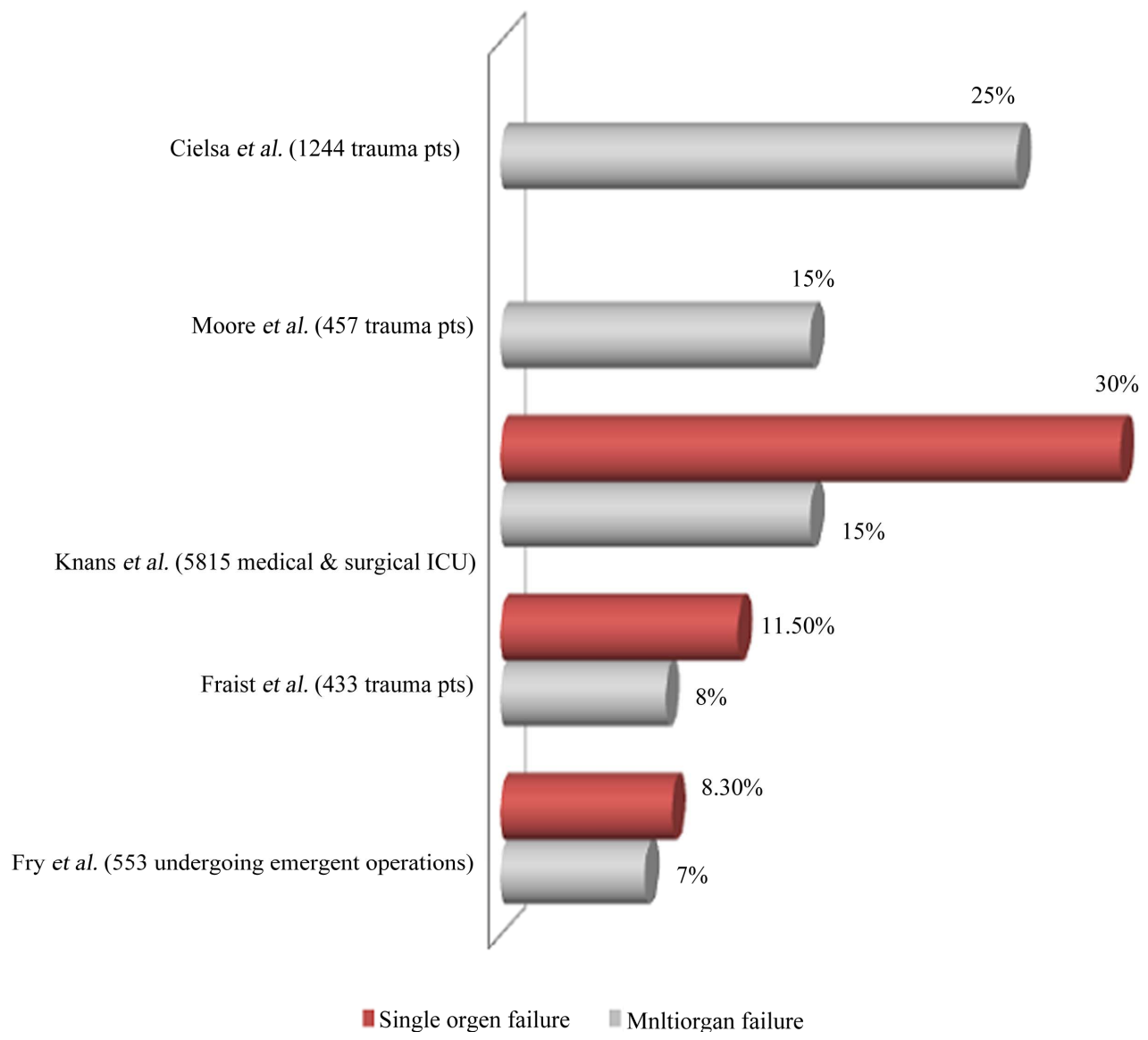

Figure 2. Incidence of organ(s) failure from western populations. 
Table 1. Different scoring systems for multiorgan failure.

\begin{tabular}{|c|c|c|}
\hline & N. of Organs & Comments \\
\hline 1) Fry et al. 1980 [15] & $\begin{array}{l}4 \text { (Pulmonary, hepatic, } \\
\text { GIT, and renal) }\end{array}$ & $\begin{array}{l}\text { One or more organs failed in } 15 \% \text { of patients. The incidence of SOF } \\
\text { and MOF were } 8.3 \% \text { and } 6.9 \% \text { and Mortality rates were } 30 \% \text { for SOF, } \\
60 \% \text { for } 2 \text { organ, } 85 \% \text { for } 3 \text {-system organ, and } 100 \% \text { for } 4-O F \text {. }\end{array}$ \\
\hline 2) Stevens 1983 [17] & 7 & Numeric Sepsis severity scoring system \\
\hline 3) Goris et al. 1985 [18] & 7 & $\begin{array}{l}\text { Organ dysfunction/failure had } 3 \text { categories: } \\
(0=\text { normal }, 1=\text { organ dysfunction, } 2=\text { OF })\end{array}$ \\
\hline 4) Knaus et al. 1985 [13] & $\begin{array}{l}5 \text { (CVS, respiratory, renal, } \\
\text { hematologic, } \\
\text { and neurological) }\end{array}$ & $\begin{array}{l}\text { One or more OFs occurred in } 49 \% \text { of patients: SOF occurred in } \approx 1 / 3 \text { of } \\
\text { patients at some time during their ICU stay. MOF occurred in } 15 \% \text {. } \\
\text { SOF lasting more than } 3 \text { days had mortality of } 40 \% \text {. Mortality was } \\
60 \% \text { for } 2 \text {-OF and } 100 \% \text { for } 3-O F \text {. }\end{array}$ \\
\hline 5) Marshall et al. 1995 (MODS) [10] & $\begin{array}{l}6 \text { (Pulmonary, renal, hepatic, } \\
\text { cardiac, hematological and } \\
\text { neurological system) }\end{array}$ & Data collected from systematic review and clinical database \\
\hline Marshall and SOFA scores & $\begin{array}{l}\text { Both scores are very sensitive but } \\
\text { a more specific score causes high }\end{array}$ & $\begin{array}{l}\text { not specific: More sensitive score causes high incidence of MODS, while } \\
\text { mortality. }\end{array}$ \\
\hline 6) Vincent et al. 1996 (SOFA) [19] & $\begin{array}{l}6 \text { (Graded from } 0 \text { to } 4 \\
\text { according to the degree of } \\
\text { dysfunction failure) }\end{array}$ & $\begin{array}{l}\text { The score individualizes the degree } \\
\text { of dysfunction of each organ obtained daily(not to predict outcome but } \\
\text { to describe a sequence of } \\
\text { complications). }\end{array}$ \\
\hline 7) Le Gall et al. 1996 (LODS) [20] & 6 & $\begin{array}{l}\text { Physiological variables of } 6 \text { organ systems by using logistic regression: } \\
\mathrm{GCS}, \mathrm{PaO}_{2}: \mathrm{FiO}_{2} \text { ratio, heart rate, } \mathrm{BP} \text {, serum urea, creatinine, urine } \\
\text { output, white blood cell, bilirubin, platelet count, and prothrombin. }\end{array}$ \\
\hline 8) Moore et al. 1996 (Denver) [12] & $\begin{array}{l}4 \text { (Pulmonary, renal, } \\
\text { hepatic and cardiac) }\end{array}$ & $\begin{array}{l}\text { One or more organ systems failed in } 25 \% \text { of patients and } 2 \text { or more } \\
\text { organ systems failed in } 15 \% \text { of patients. Mortality was } 11 \% \text { in } \\
\text { patients with } 1 \text { organ system failure, } 24 \% \text { with } 2 \text { organ systems, } \\
60 \% \text { in patients with } 3 \text { failures, and } 62 \% \text { in patients with } 4 \text { OFs. }\end{array}$ \\
\hline Denver MODS score & $\begin{array}{l}\text { To define and monitor the severit } \\
16 \text { yrs or older. Must be collected } \\
\text { hepatic and cardiac. It is more spe }\end{array}$ & $\begin{array}{l}\text { of MODS in trauma with ISS }>15 \text { who survived }>48 \text { hrs and who are } \\
\text { daily (day } 2 \text { to discharge). It rates } 4 \text { organ systems; pulmonary, renal, } \\
\text { cific and less sensitive in trauma population. }\end{array}$ \\
\hline Criteria of OF [7] & $\begin{array}{l}\text { Cardiac: Heart rate } \leq 54 \text { beats } / \mathrm{mil} \\
\text { fibrillation, or both, Serum } \mathrm{pH} \leq \\
\text { Pulmonary : Respiratory rate } \leq 5 \\
\mathrm{Hg} \text {, Dependent on ventilator on th } \\
\text { h, BUN } \geq 100 \mathrm{mg} / \mathrm{dL} \text {, Creatinine } \\
\text { transaminase greater than two tim }\end{array}$ & $\begin{array}{l}\text { Mean arterial pressure } \leq 49 \mathrm{~mm} \mathrm{Hg} \text { ventricular tachycardia, } \\
24 \text { with a PaCO } 2 \leq 49 \mathrm{~mm} \mathrm{Hg} \text {. } \\
\text { reaths } / \text { min or } \geq 49 \text { breaths } / \mathrm{min}, \mathrm{PaCO}_{2} \geq 50 \mathrm{~mm} \mathrm{Hg} \mathrm{AaDO} 2 \geq 350 \mathrm{~mm} \\
\text { e fourth day of organ failure. Renal: Urine } \leq 479 \mathrm{~mL} / 24 \mathrm{~h} \text { or } \leq 149 \mathrm{~mL} / 8 \\
3.5 \mathrm{mg} / \mathrm{dL} \text {; Hepatic: Bilirubin } \geq 3 \mathrm{mg} / \mathrm{dL} \text { Serum glutamic oxaloacetic } \\
\text { es normal Protime INR }>1.5 \text {. }\end{array}$ \\
\hline
\end{tabular}

GIT = gastrointestinal tract; $\mathrm{SOF}=$ single organ failure; $\mathrm{MOF}=$ multiorgan failure; $\mathrm{CVS}=$ cardiovascular system; ICU = intensive care unit; GCS = Glasgow coma scale; $\approx=$ approximately; $\mathrm{OF}=$ organ failure

scores performing slightly better due to greater specificity. Moreover, Denver MOF score performs better as a continuous scale to monitor individual patient's response to treatment. The analysis of individual organ dysfunction scores suggests that concepts of the two scores can be combined to develop more valid score [21].

However, what is validity and accuracy if the clinical scoring system is integrated into the biomarkers of organ dysfunction? This bio-clinical scoring has not tested yet.

\section{MODS at Cellular Level}

Numerous studies revealed that cells of the immune system (Polymorphic mononuclear [PMN], lymphocytes, monocytes/macrophages, dendritic cells and endothelial cells) and the release of pro- and anti-inflammatory cytokines, chemokines, adhesion molecules, complement, protease, eicosanoids, reactive oxygen species (ROS) and nitric oxide (NO) play a significant role in the pathogenesis of MOF. As these cells and molecules are released for primarily host defense, their release can be harmful to the host depending on the type and degree of injury, posttrauma surgery, intervention for diagnosis and therapy for trauma [22].

What is Systemic inflammatory response syndrome (SIRS)

Two or more of the following criteria are met:

-Temperature $<36.8^{\circ} \mathrm{C}$ or temperature $>38.8^{\circ} \mathrm{C}$. Heart rate $>90 / \mathrm{min}$.

-Respiratory rate $>20$ breaths $/ \mathrm{min}$ or $\mathrm{PCO}_{2}<32 \mathrm{~mm}$ $\mathrm{Hg}$.

- WBC $<4000 / \mathrm{mL}$ or $\mathrm{WBC}>12,000 \mathrm{~mL}$ or $>10 \% \mathrm{im}-$ mature forms [1].

The role of Polymorphic mononuclear (PMN) priming

It is amplification of the PMN response to a certain 
stimulus following prior exposure to a different stimulus. Clinically, priming is manifested by SIRS, characterized by alterations in body temperature, white blood cell count, respiratory dysfunction, and a hyperdynamic state. Primed PMNs cause a significant neutrophillia at $3 \mathrm{~h}$ postinjury. This neutrophillia represents the "vulnerable window" and a second hit during this period may precipitate MOF. In MOF there is a rapid neutropenia between 6 and $12 \mathrm{~h}$ postinjury (end organ sequestration). While in non-MOF, neutrophil priming and neutrophillia are not followed by neutropenia, and resolve over the next $36 \mathrm{~h}$ without end organ damage [1].

\section{MODS at the Molecular Levels}

Molecular events underlie the pathogenesis of MODS is not well-established, therefore, the temporal course of pathophysiological changes leading to the development of MODS are of great clinical and research interest. Keeping in mind "There is no gold standard diagnostic tool for MODS", however, several studies have utilized one or two biomarkers for detection of single rather than multiple organ dysfunctions. General markers of inflammation including cytokines are correlated with posttraumatic complications with a low sensitivity and specificity and are, therefore, of little utilization as prognostic markers [23]. To date, all therapeutic strategies focused on a single mediator or receptor has failed to improve the clinical outcome associated with MODS [2]. However, a recent small study showed that cytokine expression during shock may enable earlier identification of patients who are at risk for development of MODS [24].

There are only few registries and prospective studies that reported the prevalence of MODS worldwide [11,25]. Furthermore, there is no consensus to support the sensitivity and specificity, predictive values of one or more serum markers in the diagnosis or prediction of organ dysfunction before the overt clinical failure. Therapeutic strategies to combat the post injury MODS have focused on control of the post injury inflammatory response [25].

Early detection of MODS need extensive prospective studies as this will be reflected on the morbidity and mortality in all ICUs. For that purpose, ICUs should have prospective data collection on MODS in its database registry. Subsequently, registries will pave ways for the appropriate evaluation and management.

\section{Animal Models}

Trauma, shock or sepsis, researchers studied the basic mechanisms that drive the pathogenesis of end-organ injury and MODS at the cellular, tissue and whole organism levels. Previous studies demonstrated that endorgan injury and subsequent MODS result from a cause-effect relationship between three pathophysiologic events, which likely interact in a time-dependent, tissue-specific fashion. First, a persistent and progressive splanchnic vasoconstriction and hypoperfusion leading to relative ischemia/hypoxia [26,27]; Second, a gut-derived systemic inflamematory response generated by the ischemic gut [28]; and third, inevitable fluid shifts at both the cellular level due to ionic-disequilibrium and at the capillary level due to alteration of the trans-capillary Starling forces that govern fluid exchange [29,30].

\section{Gut Hypothesis}

Preclinical experimental studies showed that shock or trauma cause gut barrier failure and bacteria translocating to distant organs. Also, the subsequent gut released proinflammatory and tissue injurious factors could result in acute lung injury, bone marrow failure, myocardial dysfunction, neutrophil activation, red blood cells injury and endothelial cell activation and injury. Interestingly, these factors are carried in the mesenteric lymphatics, but not in the portal blood flow and are sufficient to cause MODS [31].

\section{The Trigger and Targeted Organ}

It has been shown that certain organs are more vulnerable and presage the chain or occurrence of MOD. There is no solid data showing whether the dysfunction will affect single organ or multiple organs. Post-traumatic lung dysfunction precedes cardiac dysfunction by 0.6 days, hepatic dysfunction by 4.8 days and renal dysfunction by 5.5 days on average $[1,4,5]$. This early involvement of the lungs supports the contention of the time dependency and tissue (organ) specificity of SIRS. The mechanism of post-traumatic lung injury and dysfunction occur at least in part through mesenteric lymph-induced activation of neutrophils and activation/injury of endothelial cells. Subsequent infiltration of the tissue with activated neutronphils is time dependent and organ specific [28]. In the shock lung, resuscitation from hemorrhagic shock secondary to trauma increases the myeloperoxidase (MPO) level, an index of neutrophil tissue infiltration, in a nearlinear fashion during the first $4 \mathrm{~h}$ following resuscitation. However, lung MPO level returned to baseline at $24 \mathrm{~h}$ following resuscitation from hemorrhagic shock [28]. This data suggest that a vulnerable window for neutron- philmediated lung damage exists during the first $4 \mathrm{~h}$ following resuscitation from hemorrhagic shock in rats [28]. Thus, demonstration of a time-dependency and organ-specificity of the proposed composite biomarkers in a fashion similar to SIRS, adds more specificity and sensitivity to the composite biomarkers, which helps the development of specific intervention before the initiation of the pathogenesis of multi-system organ failure. Figure 3 shows the inflammatory response after trauma in hrs and days [2,32-35]. 


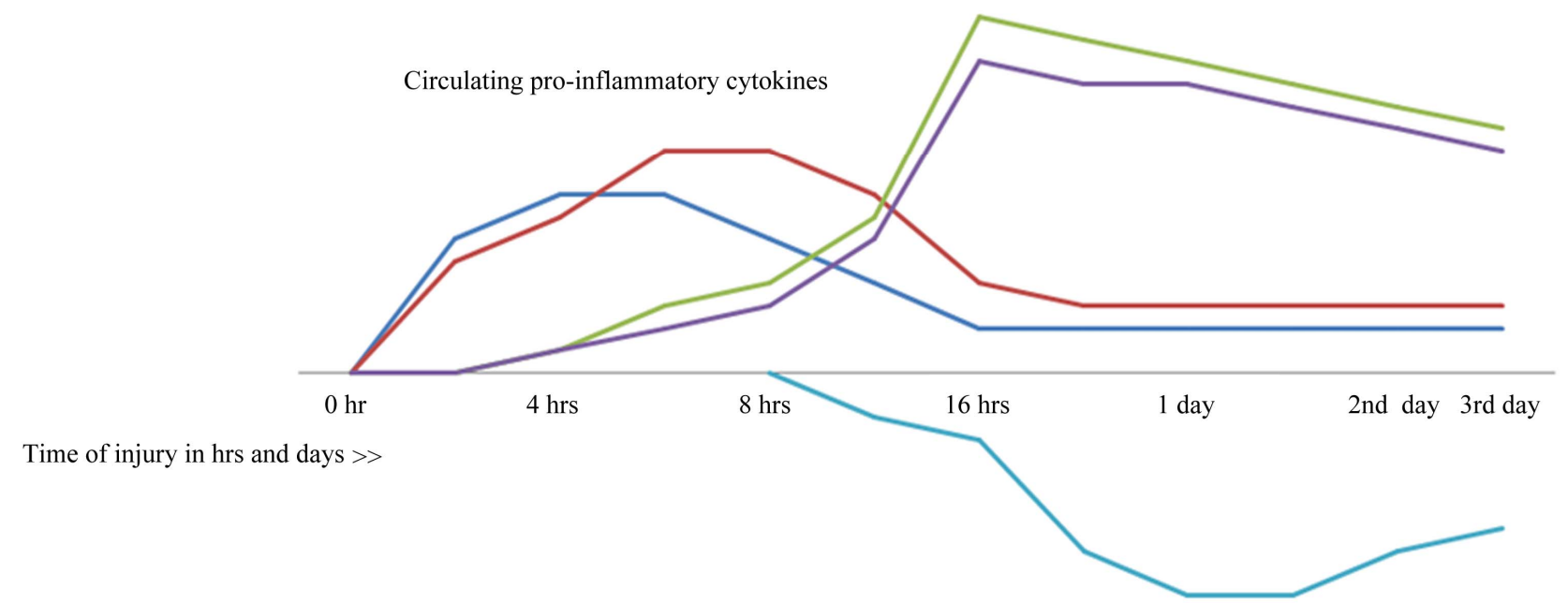

Circulating anti-inflammatory cytokines

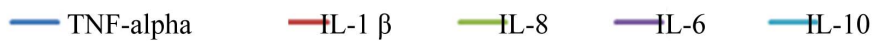

Figure 3. Cytokines response after trauma in hrs and days.

\section{Role of Biomarkers}

Different biomarkers [35-47] play various ways on the occurrence of organ dysfunction. Detailed information for the clinical utility of biomarkers is given in brief in Table 2. Certain markers have been studied frequently and prove important clinical impact on certain organs \{i.e., lung (pentraxin-3 and IL-8 \& 18), heart (NT-pro BNP, Adrenomedullin and pentraxin), kidney (NGAL) and liver (glutamate/glutamine and cytokeratin-18) $\}$ in addition to Vascular cell adhesion molecule (VCAM-1) and Endothelial cell-specific molecule 1 (ESM-1) [48]. Biomarkers for early detection of sepsis (i.e., procalcitonin) is also important. Several studies tackling proinflammtory (i.e., IL-8 \&18) and anti-inflammatory (i.e., IL-6 \&10) cytokines have shown that there is no single cytokine turned out to be legible enough to predict the outcome [35].

The cytokine response is an important factor in the development of SIRS as a response to trauma. Pro-and anti-inflammatory cytokines are released excessively during the initial phase of trauma. The role of the anti-inflammatory cytokines is to down-regulate the production of pro-inflammatory cytokines. Normally, the bala nce of pro- and anti-inflammatory cytokines is in equilibrium, however, when this natural balance is unbalanced with the release of predominantly pro-inflammatory cytokines, this leads to SIRS, while predominance of anti-inflammatory cytokines causes immunosuppression, which lead to infection, sepsis and subsequently result in MOF [22]. The role of acute phase proteins: Levels of CRP rapidly increase within 2 hours of acute insult, reaching a peak at 48 hours. With resolution of the acute phase response, CRP declines with a relatively short half-life of 18 hours. PCT is proposed to be a better and more specific marker for inflammation than CRP, as the kinetics of PCT more closely resembles the kinetics of inflammation [37,38]. Serum levels of PCT more rapidly increase after the onset of inflammation and decline faster as inflammation diminishes.

\section{Recommendation and Conclusion}

Bring up new bio-clinical scoring to a stage where it is ready for field trials will pave the way for implementing new risk-stratification strategy in the intensive care to reduce the morbidity and mortality and save resources.

Further trials will be based on that to establish preventive measures and goal-targeted therapy in the ICUs. Understanding the different pathphysiology of early MODS will discriminate the signs of intense inflammatory response from early signs of sepsis. This will reduce the inappropriate use of antibiotics or to correctly start antibiotics at the early stages of sepsis and subsequently reduce hospital stay and mortality. As there are no guidelines or consensus for management of high-risk patients, further studies utilizing the integrated bio-clinical hypothesis will be of great interest. Further prospective studies are needed to answer our question and convert MODS from inevitable to preventable disorder. 
Table 2. Biomarkers play a role in MODS.

\section{Biomarker}

1) Neutrophil gelatinase-associated lipocalin (NGAL)

2) Serum glutamate/glutamine

3) Cytokeratin-18 (CK-18)

4) Procalcitonin $(\mathrm{PCT})$

5) Adrenomedullin (AM)

6) Pentraxin-3 (PTX3)

7) NT-pro-BNP

8) VCAM-1

9) Cytokines (interleukine; IL)

\section{REFERENCES}

[1] D. Dewar, F. A. Moore, E. E. Moore and Z. Balogh, "Postinjury Multiple Organ Failure," Injury, Vol. 40, No. 9, 2009, pp. 912-918. doi:10.1016/j.injury.2009.05.024

[2] B. Maier, R. Lefering, M. Lehnert, H. L. Laurer, W. I. Steudel, E. A. Neugebauer and I. Marzi, "Early versus Late Onset of Multiple Organ Failure Is Associated with Differing Patterns of Plasma Cytokine Biomarker Expression and Outcome after Severe Trauma," Shock, Vol. 28, No. 6, 2007, pp. 668-674.

[3] D. Dewar, N. Butcher, K. King and Z. Balogh, "Post Injury Multiple Organ Failure," Trauma, Vol. 13, No. 1, 2011, pp. 81-91.

[4] D. J. Ciesla, E. E. Moore, J. L. Johnson, A. Sauaia, C. C.
Clinical utility

NGAL is ideal biomarker for acute kodney injury (AKI); its concentration rapidly decreases with attenuation $48 \mathrm{~h}$ earlier than creatinine.

utamine itself may act as a key precursor for nucleic acids in glutamine consuming cells, but in many glutamine.. Glutamate could be a marker of liver dysfunction during sepsis

-18 presents in most simple epithelial and parenchymal cells. Fragments of CK-18 are more specific for

PCT supports early diagnosis and clinical decision making which could direct an effective therapy at the clined rapidly after trauma. The rapid decline of the trauma-induced response of PCT towards its normal range compared with the long-lasting increase of CRP promises an earlier diagnostic use of PCT as a marker

AM production and secretion is augmented by several pro-inflammatory and pro-atherogenic factors. Circulating adrenomedullin levels are elevated in acute cardiac injury. plasma levels are markedly increased DS score during the first month and prognosis in patients with septic shock, as did plasma IL-6 levels in PTX3 is a rapid marker for primary local activation of innate immunity and inflammation It is associated with acute lung and heart injury. PTX3 behaves as an acute phase response protein, as the blood levels of dramatically $(200-800 \mathrm{ng} / \mathrm{mL})$ during endotoxic shock, sepsis and correlating with the severity of the

NT-proBNP, is supposed to be a better marker of myocardial dysfunction and prognosis in patients with evere sepsis and septic shock. Its levels correlate with the severity of organ dysfunction as assessed by the SOFA score in septic patients. The half-life of human NT-proBNP is considered to be $60-120 \mathrm{~min}$

Vascular cell adhesion protein 1 is also known as vascular cell adhesion molecule 1 .VCAM-1 protein mediates the adhesion of lymphocytes, monocytes, eosinophils, and basophils to vascular endothelium. It

MODS is associated with higher levels of systemic proinflammatory cytokines(IL6, IL8 and IL10). Patients following trauma leads to leucocyte recruitment and activation at the site of injury.

contrast to NT-proBNP and PCT,initial IL-6 are highly predictor of mortality after myocardial infarction ARDS and MODS.

Inflammatory cytokines such as TNF- $\alpha$ strongly stimulate human endothelial cell to increase the secretion, thesis and expression of endocan. Studies agreed on the endocan's prognostic value and how it could be of huge help to predict the outcome of sepsis. As its increase at ICU admission is indicative of poor prognosis.
Cothren, J. B. Moore and J. M. Burch, "Multiple Organ Dysfunction during Resuscitation Is Not Postinjury Multiple Organ Failure," Archives of Surgery, Vol. 139, No. 6, 2004, pp. 590-594. doi:10.1001/archsurg.139.6.590

[5] D. J. Ciesla, E. E. Moore, J. L. Johnson, et al., "The Role of the Lung in Postinjury Multiple Organ Failure," Surgery, Vol. 138, No. 4, 2005, pp. 749-757. doi:10.1016/j.surg.2005.07.020

[6] F. A. Moore, A. Sauaia, E. E. Moore, et al., "Postinjury Multiple Organ Failure: A Bimodal Phenomenon," Journal of Trauma, Vol. 40, No. 4, 1996, pp. 501-502. doi:10.1097/00005373-199604000-00001

[7] R. M. Durham, J. J. Moran, J. E. Mazuski, M. J. Shapiro, A. E. Baue and L. M. Flint, "Multiple Organ Failure in 
Trauma Patients," Journal of Trauma, Vol. 55, No. 4, 2003, pp. 608-616. doi:10.1097/01.TA.0000092378.10660.D1

[8] R. Bone, R. Balk, F. Cerra, et al., "Definitions for Sepsis and Organ Failure and Guidelines for the Use of Innovative Therapies in Sepsis: The ACCP/SCCM Consensus Conference Committee-American College of Chest Physicians/Society of Critical Care Medicine," Chest, Vol. 101, No. 6, 1992, pp. 1644-1655.

[9] J. Marshall, "A Scoring System for the Multiple Organ Dysfunction Syndrome (MODS)," In: K. Rheinhart, K. Eyrich and C. Sprung, Eds., Sepsis: Current Perspectives in Pathophysiology and Therapy, Springer-Verlag, Berlin, 1994, pp. 38-49.

[10] J. Marshall, D. Cook, N. Christou, G. Bernard, C. Sprung and W. Sibbald, "Multiple Organ Dysfunction Score: A Reliable Descriptor of a Complex Clinical Outcome," Critical Care Medicine, Vol. 23, No. 10, 1995, pp. 1638-1652.

[11] D. J. Ciesla, E. E. Moore, J. L. Johnson, J. M. Burch, C. C. Cothren and A. Sauaia, "A 12-Year Prospective Study of Postinjury Multiple Organ Failure: Has Anything Changed?" Archives of Surgery, Vol. 140, No. 5, 2005, pp. 432-438. doi:10.1001/archsurg. 140.5.432

[12] F. A. Moore, A. Sauaia, E. E. Moore, et al., "Postinjury Multiple Organ Failure: A Bimodal Phenomenon," Journal of Trauma, Vol. 40, No. 4, 1996, pp. 501-502. doi:10.1097/00005373-199604000-00001

[13] W. A. Knaus, E. A. Draper, D. P. Wagner and J. E. Zimmerman, "Prognosis in Acute Organ System Failure," Annals of Surgery, Vol. 202, No. 6, 1985, pp. 685-693. doi:10.1097/00000658-198512000-00004

[14] E. Faist, A. E. Baue, H. Dittmer, G. Heberer, "Multiple Organ Failure in Polytrauma Patients," Journal of Trauma, Vol. 23, No. 9, 1983, pp. 775-787. doi:10.1097/00005373-198309000-00002

[15] D. E. Fry, L. Pearlstein, R. L. Fulton and H. C. Polk, "Multiple System Organ Failure: The Role of Uncontrolled Infection," Archives of Surgery, Vol. 115, No. 2, 1980, pp. 136-140.

[16] H. G. Cryer, K. Leong, D. L. McArthur, et al., "Multiple Organ Failure: By the Time You Predict It, It's Already There," Journal of Trauma, Vol. 46, No. 4, 1999, pp. 597604. doi:10.1097/00005373-199904000-00007

[17] L. E. Stevens, "Gauging the Severity of Surgical Sepsis," Archives of Surgery, Vol. 118, No. 10, 1983, pp. 11901192. doi:10.1001/archsurg.1983.01390100060015

[18] R. J. Goris, T. P. te Boekhorst, J. K. Nuytinck and J. S. Gimbree, "Multiple-Organ Failure: Generalized Autodestructive Inflammation?" Archives of Surgery, Vol. 120, No. 10, 1985, pp. 1109-1115. doi:10.1001/archsurg.1985.01390340007001

[19] J. L. Vincent, R. Moreno, J. Takala, et al., "The SOFA (Sepsis-related Organ Failure Assessment) Score to Describe Organ Dysfunction/Failure," Intensive Care Medicine, Vol. 22, No. 7, 1996, pp. 707-710. doi:10.1007/BF01709751

[20] J. R. Le Gall, J. Klar, S. Lemeshow, et al., "ICU Scoring Group. The Logistic Organ Dysfunction System: A New Way to Assess Organ Dysfunction in the Intensive Care
Unit," Journal of the American Medical Association, Vol. 276, No. 10, 1996, pp. 802-810. doi:10.1001/jama.1996.03540100046027

[21] A. Sauaia, E. E. Moore, J. L. Johnson, D. J. Ciesla, W. L. Biffl and A. Banerjee, "Validation of Postinjury Multiple Organ Failure Scores," Shock, Vol. 31, No. 5, 2009, pp. 438-447. doi:10.1097/SHK.0b013e31818ba4c6

[22] T. Tsukamoto, R. S. Chanthaphavong and H. C. Pape, "Current Theories on the Pathophysiology of Multiple Organ Failure after Trauma," Injury, Vol. 41, No. 1, 2010, pp. 21-26. doi:10.1016/j.injury.2009.07.010

[23] S. Oda, H. Hirasawa, T. Sugai, et al., "Comparison of Sepsis Related Organ Failure Assessment (SOFA) Score and CIS (Cellular Injury Score) for Scoring of Severity for Patients with Multiple Organ Dysfunction Syndrome (MODS)," Intensive Care Medicine, Vol. 26, No. 12, 2000, pp. 1786-1793. doi:10.1007/s001340000710

[24] V. Pettila, M. Pettila, S. Sarna, P. Voutilainen and O. Takkunen, "Comparison of Multiple Organ Dysfunction Scores in the Prediction of Hospital Mortality in the Critically Ill," Critical Care Medicine, Vol. 30, No. 8, 2002, pp. 1705-1711. doi:10.1097/00003246-200208000-00005

[25] D. C. Dewar, P. Mackay and Z. Balogh, "Epidemiology of Post-Injury Multiple Organ Failure in an Australian Trauma System," ANZ Journal of Surgery, Vol. 79, No. 6, 2009, pp. 431-436. doi:10.1111/j.1445-2197.2009.04968.x

[26] E. R. Zakaria, R. N. Garrison, D. A. Spain, P. J. Matheson, P. D. Harris and D. J. Richardson, "Intraperitoneal Resuscitation Improves Intestinal Blood Flow Following Hemorrhagic Shock," Annals of Surgery, Vol. 237, No. 5, 2003, pp. 704-713.

doi:10.1097/01.SLA.0000064660.10461.9D

[27] E. R. Zakaria, R. T. Hurt, P. J. Matheson and R. N. Garrison, "A Novel Method of Peritoneal Resuscitation Improves Organ Perfusion after Hemorrhagic Shock," American Journal of Surgery, Vol. 186, No. 5, 2003, pp. 443448. doi:10.1016/j.amjsurg.2003.07.006

[28] E. R. Zakaria, J. E. Campbell, J. C. Peyton and R. N. Garrison, "Post-Resuscitation Tissue Neutrophil Infiltration Is Time-Dependent and Organ-Specific," Journal of Surgical Research, Vol. 143, No. 1, 2007, pp. 119-125. doi:10.1016/j.jss.2007.04.008

[29] E. R. Zakaria, P. J. Matheson, M. F. Flessner and R. N. Garrison, "Hemorrhagic Shock and Resuscitation-Mediated Tissue Water Distribution Is Normalized by Adjunctive Peritoneal Resuscitation," Journal of the American College of Surgeons, Vol. 206, No. 5, 2008, pp. 970-980. doi:10.1016/j.jamcollsurg.2007.12.035

[30] E. R. Zakaria, N. Li, P. J. Matheson and R. N. Garrison, "Cellular Edema Regulates Tissue Capillary Perfusion Following Hemorrhage Resuscitation," Surgery, Vol. 142, No. 4, 2007, pp. 487-496. doi:10.1016/j.surg.2007.08.007

[31] E. A. Deitch, "Gut-Origin Sepsis: Evolution of a Concept," The Surgeon, Vol. 10, No. 6, 2012, pp. 350-356. doi:10.1016/j.surge.2012.03.003

[32] Z. Lausevic, M. Lausevic and J. Trbojevic-Stankovic, "Predicting Multiple Organ Failure in Patients with Severe Trauma," Canadian Journal of Surgery, Vol. 51, No. 2, 2008, 
pp. 97-102.

[33] R. M. Roumen, H. Redl and G. Schlag, "Inflammatory Mediators in Relation to the Development of Multiple Organ Failure in Patients after Severe Blunt Trauma," Critical Care Medicine, Vol. 23, No. 3, 1995, pp. 474-480.

[34] P. V. Giannoudis, "Current Concepts of the Inflammatory Response after Major Trauma: An Update," Injury, Vol. 34, No. 6, 2003, pp. 397-404.

[35] T. Visser, J. Pillay, L. Koenderman and L. P. Leenen, "Postinjury Immune Monitoring: Can Multiple Organ Failure Be Predicted?" Current Opinion in Critical Care, Vol. 14, No. 6, 2008, pp. 666-672. doi:10.1097/MCC.0b013e3283196522

[36] A. M. Ferreira and Y. Sakr, "Organ Dysfunction: General Approach, Epidemiology, and Organ Failure Scores," Seminars in Respiratory and Critical Care Medicine, Vol. 32, No. 5, 2011, pp. 543-551. doi:10.1055/s-0031-1287862

[37] R. M. Dorizzi, E. Polati and P. Sette, "Procalcitonin in the Diagnosis of Inflammation in Intensive Care Units," Clinical Biochemistry, Vol. 39, No. 12, 2006, pp. 1138-1143.

[38] A. Luzzani, E. Polati and R. Dorizzi, "Comparison of Procalcitonin and C-Reactive Protein as Markers of Sepsis," Critical Care Medicine, Vol. 31, No. 6, 2003, pp. 17371741. doi:10.1097/01.CCM.0000063440.19188.ED

[39] M. Krueger, A. Heinzmann and M. Nauck, "Adhesion Molecules in Pediatric Intensive Care Patients with Organ Dysfunction Syndrome," Intensive Care Medicine, Vol. 33, No. 2, 2007, pp. 359-363. doi:10.1007/s00134-006-0453-6

[40] S. Hofer, T. Brenner, C. Bopp, J. Steppan, C. Lichtenstern, J. Weitz, T. Bruckner, E. Martin, U. Hoffmann and M. A. Weigand, "Cell Death Serum Biomarkers Are Early Predictors for Survival in Severe Septic Patients with Hepatic Dysfunction," Critical Care, Vol. 13, No. 3, 2009, pp. R93. doi:10.1186/cc7923

[41] N. Kume, H. Mitsuoka, K. Hayashida and M. Tanaka, "Pentraxin 3 as a Biomarker for Acute Coronary Syndrome: Comparison with Biomarkers for Cardiac Damage," Journal of
Cardiology, Vol. 58, No. 1, 2011, pp. 38-45. doi:10.1016/j.jjcc.2011.03.006

[42] X. He, B. Han, X. Bai, Y. Zhang, M. Cypel, M. Mura, S. Keshavjee and M. Liu, "PTX3 as a Potential Biomarker of Acute Lung Injury: Supporting Evidence from Animal Experimentation," Intensive Care Medicine, Vol. 36, No. 2, 2010, pp. 356-364. doi:10.1007/s00134-009-1720-0

[43] M. Haase, P. Devarajan, A. Haase-Fielitz, et al., "The Outcome of Neutrophil Gelatinase-Associated LipocalinPositive Subclinical Acute Kidney Injury: A Multicenter Pooled Analysis of Prospective Studies," Journal of the American College of Cardiology, Vol. 57, No. 17, 2011, pp. 1752-1761. doi:10.1016/j.jacc.2010.11.051

[44] I. T. Klip, A. A. Voors, S. D. Anker, H. L. Hillege, et al., "OPTIMAAL Investigators Prognostic Value of Mid-Regional Pro-Adrenomedullin in Patients with Heart Failure after an Acute Myocardial Infarction," Heart, Vol. 97, No. 11, 2011, pp. 892-898.

[45] C. Kirchhoff, B. A. Leidel, S. Kirchhoff, V. Braunstein, V. Bogner, U. Kreimeier, W. Mutschler and P. Biberthaler, "Analysis of N-Terminal Pro-B-Type Natriuretic Peptide and Cardiac Index in Multiple Injured Patients: A Prospective Cohort Study," Critical Care, Vol. 12, No. 5, 2008, p. R118. doi:10.1186/cc7013

[46] M. Poeze, Y. C. Luiking, P. Breedveld, S. Manders and N. E. Deutz, "Decreased Plasma Glutamate in Early Phases of Septic Shock with Acute Liver Dysfunction Is an Independent Predictor of Survival," Clinical Nutrition, Vol. 27, No. 4, 2008, pp. 523-530. doi:10.1016/j.clnu.2008.04.006

[47] S. Hofer, T. Brenner, C. Bopp, et al., "Cell Death Serum Biomarkers Are Early Predictors for Survival in Severe Septic Patients with Hepatic Dysfunction," Critical Care, Vol. 13, No. 3, 2009, p. R93. doi:10.1186/cc7923

[48] P. Paulus, C. Jennewein and K. Zacharowski, "Biomarkers of Endothelial Dysfunction: Can They Help Us Deciphering Systemic Inflammation and Sepsis?" Biomarkers, Vol. 16, Suppl. 1, 2011, pp. S11-S21. doi:10.3109/1354750X.2011.587893 